\title{
Early and preventable changes of peripheral nerve structure and function in insulin-deficient diabetic rats
}

\author{
J . J A K O B S E N
}

From the University Institute of Pathology, Department of Cell Biology, Institute of Anatomy, Institute of Physiology, and Second University Clinic of Internal Medicine, Kommunehospitalet, Aarhus, Denmark

SUMMARY Structure and function of peripheral nerve in early insulin deficient streptozotocin diabetic rat were examined. Quantitative studies of myelinated fibres from electron micrographs showed that fibre calibre and slope coefficients of regression lines between axon and myelin areas were reduced and quantitation of unmyelinated fibres revealed a $40 \%$ reduction in area fraction of smooth endoplasmic reticulum. The difference in conduction velocity between diabetic rats and control rats increased with time just as does the difference in fibre calibre. Insulin treatment was able to prevent the decrease in conduction velocity as well as the reduction in fibre calibre. It is concluded that the early structural axon abnormality results from the diabetic state and cannot be explained by poor general condition of the animals.

After several years of diabetes some patients develop symptoms of peripheral neuropathy (Lundbæk, 1953). Nerve function is considerably disturbed in most long-term diabetics and nerve structure is severely damaged including segmental demyelination and axonal loss (Thomas and Lascelles, 1966; Reske-Nielsen and Lundbæk, 1968; Chopra et al., 1969).

In early insulin-deficiency juvenile diabetes, motor nerve conduction velocity is slightly reduced (Gregersen, 1967). If the metabolic state is normalised or nearly normalised, as can be done for a few weeks during hospitalisation, conduction improves. When the metabolic state deteriorates by withdrawal of insulin treatment, motor conduction is again slowed (Gregersen, 1968a). The same is true for peripheral nerve function during ischaemia (Gregersen, 1968b). These results indicate that the nerve abnormalities demonstrable by these neurophysiological techniques are caused by the metabolic derangement which characterises the diabetic state.

There is very little information on the structural

This study was supported by Grant 512-10145 from the Danish Medical Research Council.

Address for reprint requests: Dr Johannes Jakobsen, Anatomisk Institut, Universitetsparken DK-8000 Aarhus C, Denmark.

Accepted 6 November 1978 background of these functional changes in early juvenile diabetes. One reason for this is, of course, that physicians hesitate to do nerve biopsies in recently diagnosed young patients without symptoms of peripheral neuropathy.

In experimental insulin-deficiency diabetes, nerve conduction and peripheral nerve function during ischaemia are known to be changed as in early juvenile diabetes (Eliasson, 1964; Seneviratne and Peiris, 1969). Light microscopic studies in our laboratory have shown changes in the fibre calibre corresponding quantitatively to the functional abnormalities (Jakobsen, 1976a; Jakobsen and Lundbæk, 1976).

This conclusion has been criticised by Thomas and Sharma (1976) and Sharma et al. (1977). They suggested that what we had found is not a nerve change caused by the metabolic abnormality characterising the diabetic state of the animals, but just an expression of general poor health with retardation of growth in length.

We have, therefore, repeated our experiments this time including measurements of skeletal growth. The results obtained show that in our experimental arrangements skeletal length is identical in diabetic and control animals.

Furthermore, we have extended our studies of early structural nerve changes by an electron microscopic quantitation of calibre of myelinated 
and unmyelinated fibres, axon-myelin ratios and of axon organelles. In order to find out whether the slowing of nerve conduction was correlated with the difference in fibre calibre, conduction velocity was examined with respect to duration of diabetes. Finally, prevention of the structural and functional nerve abnormalities occurring in streptozotocin diabetic rat was attempted by insulin treatment.

\section{Materials and methods}

Male Wistar rats were used throughout these experiments. With the exceptions noted below all the rats were 28 weeks old at the time of sacrifice or determination of nerve conduction velocity.

For the study of age changes in normal rats, groups of animals were examined at the age of 24 and 28 weeks (body weight $350-450 \mathrm{~g}$ ), and at the age of 48 weeks (body weight $360-505 \mathrm{~g}$ ).

Skeletal growth in diabetic animals were studied in a group of 10 animals aged 24 weeks which had been diabetic for four weeks. An age- and weight-matched group of 10 control rats was used for comparison (body weight 330-380 $\mathrm{g}$ at the age of 20 weeks). Skeletal growth was also studied in the group of 48 week old rats $(n=10)$ mentioned above.

The effect of insulin on nerve structure was studied in a group of rats which had been treated with insulin for four weeks from the induction of diabetes at the age of 24 weeks.

Ultrastructural investigations were performed at electron microscopy on material available from our earlier study (Jakobsen, 1976a). The rats were 23-24 weeks old and had had diabetes for four weeks. Age- and weight-matched control rats were used for comparison (body weight 330-380 $\mathrm{g}$ at the age of 19-20 weeks).

- Nerve conduction velocity was determined in four groups of diabetic rats, all aged 28 weeks, but with a duration of diabetes between 10-18 hours and five weeks. A control group and a group of diabetic rats treated with insulin for two weeks were also included in these neurophysiological studies (body weight $350-450 \mathrm{~g}$ at the time of selection for the experiment).

Diabetes was induced by intravenous injection of $40-45 \mathrm{mg}$ streptozotocin per $\mathrm{kg}$ body weight, and only rats having a blood glucose value above $13.9 \mathrm{mniol} \mathrm{l}^{-1}(250 \mathrm{mg} / \mathrm{dl}) 24$ hours after the injection entered the experiments. Blood glucose was determined with Dextrostix and an Ames reflectance meter.

A long-acting insulin preparation (modified Ultralente, $\mathrm{pH}$ 5.5), kindly provided by $\mathrm{Dr}$ J. Schlichtkrull, Novo Research Institute, was used in this study (Rasch, 1979). Insulin was given daily at noon, and the dose was selected according to blood glucose determinations made just before the injection. The first insulin dose was given 24 hours after the application of streptozotocin and the last one less than 24 hours before the final experiments. The insulin dose given within the first week was reduced gradually from 8-4 iu per day till it was stabilised at about 3 iu per day. It was intended to keep the blood glucose as close to normal values as possible. Values between 3.3 and $6.7 \mathrm{mmol}{ }^{-1}(60$ and $120 \mathrm{mg} / \mathrm{dl})$ were accepted without leading to a change of the insulin dose. Blood glucose was determined every two hours in a 24 hour period two weeks after the start of the experiment. Five animals with values between 3.3 and $6.7 \mathrm{mmol}^{-1}$ that day were selected for the experiment.

Skeletal growth was estimated by measuring tibial length. The tibia was freed from connective tissues, the cartilages were left intact and the measurement of the wet bone was performed with calipers.

\section{LIGHT MICROSCOPY}

The common peroneal nerves were fixed by vascular perfusion, through the abdominal aorta under controlled pressure, with a cacodylate buffered paraformaldehyde-glutaraldehyde fixative. The osmolarity of buffer and fixative was measured by freezing point depression and maintained within narrow limits. A 10-20 mm long specimen of the nerve was taken just above the knee, postfixed in $2 \%$ osmium tetroxide, rinsed in buffer, dehydrated in graded acetone and embedded in Vestopal. Thin transverse sections $(0.1-$ $0.2 \mu \mathrm{m})$ were cut on an LKB-Ultrotome and stained with toluidine blue. Transverse sections were obtained by placing the nerve axis perpendicular to the glass knife by means of a 10 times magnifying ocular fitted with cross hairs.

To obtain representative samples of central as well as of peripheral parts of the nerve, crosssection sampling was made within circle sectors placed at random on the image of the section. Myelinated fibres were counted and measured within two sectors making up one-eighth of the nerve area. Fascicular area, endoneurial area, sector area, and fibre area were all estimated by a point-counting technique (see Elias et al., 1971; Weibel and Bolender, 1973) at magnifications and point densities as previously described by Jakobsen (1976a). The endoneurial area in this part of the study means the fascicular area minus the myelinated fibre area and the vessel area (see Jakobsen, 1978). 
The reason why area estimation of fibre calibre was performed instead of measuring "fibre diameter" is that the cross-sectional area is an unbiased estimate whereas "fibre diameter" is a rough estimate because fibre profiles are neither circles nor ellipses. An important consequence of this often neglected fact is that measurements of "diameter" may lead to errors when fibres of different shapes are compared. In such situations, the fibre "diameter" may change in a way inconsistent with the relation between diameter and area. This, of course, may well be the case in studies of pathological conditions.

\section{ELECTRON MICROSCOPY}

The nerves used for the ultrastructural study were fixed, dehydrated, and embedded as described above. A sample corresponding to about $14 \%$ of the fascicular area was obtained by trimming a small pyramid which did not include the centre of the nerve. Ultrathin sections of the sample were cut on an LKB-Ultrotome and stained with uranyl magnesium acetate and lead citrate. Electron microscopy was carried out with a Philips EM 200, and the micrographs of the selected part of the common peroneal nerve were pasted together to form one composite picture, which included an average of nearly 250 myelinated fibres. The magnification was checked by photographing a carbon grating grid on each film. Its average value was 13500 times.

When measuring myelinated fibres on electron micrographs a sampling problem is present. Fibres cut by the border of the micrographs cannot be measured. Since small fibres can be measured closer to the border than larger ones, the smaller fibres are over-represented. This problem was solved by drawing a frame at the distance of one large fibre diameter from the inside of the border of the photomontage. In this way fibres cut by the montage were omitted, while fibres divided by the frame were included in proportion to the part of them which lay inside the frame.

The size of the test area was estimated with a point density of one point per $45 \mu \mathrm{m}^{2}$, and the number of fibres in the common peroneal nerve was obtained by multiplying the number of fibres within the test area by the ratio between the fascicular area determined at light microscopy and the test area.

Fibre, axon, and myelin areas were estimated with a point density of one point per $5 \mu \mathrm{m}^{2}$. Only points falling upon compact myelin were counted, excluding incisures of Schmidt-Lanterman and areas of myelin splitting.

The number of mitochondrial profiles and smooth endoplasmic reticulum (SER) profiles within all myelinated fibres in the test area, and the total areas of these organelles were estimated using a point density of one point per $0.13 \mu \mathrm{m}^{2}$. Mitochondria were defined in this study as dark organelles with inner structure and SER as light organelles without inner structure.

The density of neurofilaments was estimated by counting the number of filaments within 10 small quadrants of $0.09 \mu \mathrm{m}^{2}$ within each of 10 myelinated axons per animal. Randomised selection of $\mathbf{1 0}$ numbered fibres was obtained by means of a table of random numbers.

Measurements of unmyelinated nerve fibres were started in the upper left corner of each photomontage and stopped when the counts exceeded 200 fibres (range, 207-257). The numbers of mitochondrial profiles and SER profiles within these fibres were counted, and fibre size, mitochondrial, and SER areas were estimated with a point density of one point per $0.11 \mu \mathrm{m}^{2}$.

\section{CONDUCTION VELOCITY}

To minimise the variation of length measurements and temperature in determinations of nerve conduction velocity of the largest fibres the tail nerve was used (Miyoshi and Goto, 1973). The rats were anaesthetised mildly with a sodium pentobarbitonediazepam mixture, and the left ventral tail nerve was exposed surgically 60 and $120-140 \mathrm{~mm}$ from the anus, and cut distally.

The tail was lead into a vessel in the wall of which thermostated water was circulating. Subsequently the vessel was filled with paraffin, and the temperature of the paraffin bath was maintained between $37.5^{\circ} \mathrm{C}$ and $38.5^{\circ} \mathrm{C}$. Before the experiments the tail was kept in the bath for 20 minutes reducing the temperature difference between the paraffin and the subcutis of the tail to less than $0.3^{\circ} \mathrm{C}$. Then the nerve was placed on $\mathrm{J}$-shaped $0.15 \mathrm{~mm}$ thin platin electrodes and stimulated proximally with single rectangular current pulses. The propagated action potentials were recorded distally. Stimuli with a duration of 0.05 msec supramaximal to the fastest conducting fibres were delivered from a stimulator at a frequency of $10 / \mathrm{s}$. Thirty consecutive action potentials were displayed on a Medelec ${ }^{\mathrm{R}}$ oscilloscope, superimposed and photographed with a time scale. The distance between the two pairs of electrodes was measured before and after stimulation with a pair of pointed-leg calipers using the mean value for calculation of conduction velocity.

The rats used in the experiments for ultrashort duration of diabetes had had blood glucose values above $11.1 \mathrm{mmol} \mathrm{l}^{-1}(200 \mathrm{mg} / \mathrm{dl})$ for $10-18$ hours. 
At the time when the determination was performed the average blood glucose was $16.2 \mathrm{mmol}^{-1}$ (range 13.9-18.3 $\mathrm{mmol} \mathrm{l}^{-1}$ ).

Student's $t$ test was employed in the statistical treatment using a $5 \%$ limit of significance.

\section{Results}

BLOOD GLUCOSE, BODY WEIGHT, AND TIBIAL LENGTH At the time of the experiments blood glucose ranged between 16.9 and $28.0 \mathrm{mmol} 1^{-1}$ (mean, $23.0 \mathrm{mmol} \mathrm{1^{-1 }}$ ) in untreated diabetic rats. In the groups of rats with four weeks duration of diabetes the weight loss ranged between 50 and $130 \mathrm{~g}$, the mean value being $91 \mathrm{~g}$. After one, two, and five weeks duration of diabetes the mean weight loss was 47,66 , and $104 \mathrm{~g}$, respectively.

Insulin-treated rats all survived and all gained weight. The weight increase after four weeks of treatment was $17 \mathrm{~g}$ (range, 5-35 g). In the group of two weeks of insulin treatment the mean weight increase was $12 \mathrm{~g}$ (range, $0-25 \mathrm{~g}$ ).

Blood glucose values measured 24 hours after the daily insulin injection were $3.3,4.9$, and 7.9 mmol $1^{-1}$ when given by the 20th, 50th, and 80th percentiles. In other words blood glucose ranged between 3.3 and 7.9 mmol $1^{-1} 24$ hours after the daily insulin injection in three of five days, the median being $4.9 \mathrm{mmol} 1^{-1}$. The corresponding

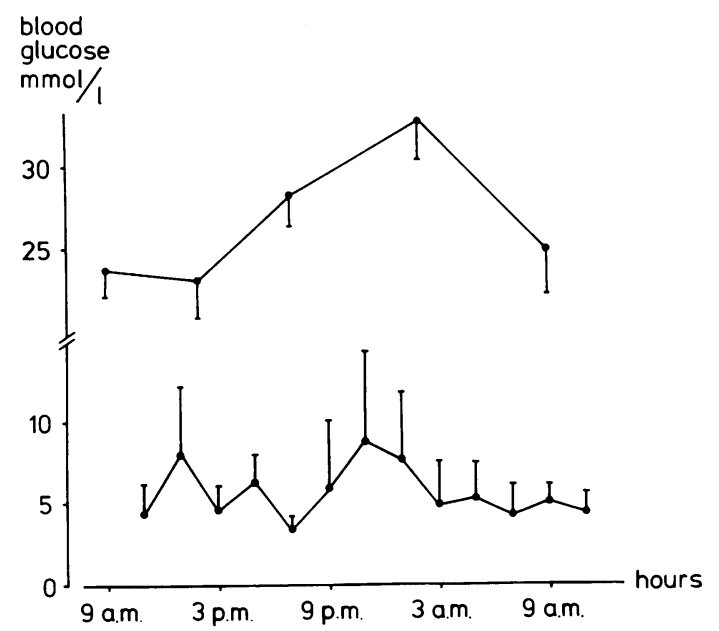

Fig. 1 Lower curve: mean values and standard deviations of blood glucose measurements at two hour intervals during a 24 hour period in a group of five insulin-treated diabetic rats. Upper curve: for comparison mean blood glucose values and standard deviations at five to seven hour intervals in a group of five untreated diabetic rats. percentile values of the two weeks treated group used in the neurophysiological experiments were $3.8,5.4$ and $8.2 \mathrm{mmol} \mathrm{1}^{-1}$.

The blood glucose variation during the 24 hour period in insulin treated rats with initial values ranging between 3.3 and $6.7 \mathrm{mmol} \mathrm{1}^{-1}$ is illustrated in Fig. 1. The mean value of all measurements was $5.7 \mathrm{mmol}^{1-1}$ and the mean values of the various time intervals ranged between 3.4 and 8.8 mmol $1^{-1}$.

The individual values of the measurements of tibial length in control and age-matched diabetic animals are shown in Fig. 2. Nearly identical values were obtained, $42.7 \mathrm{~mm} \pm 0.7$ (SD) and $42.5 \mathrm{~mm} \pm 1.0$, respectively. In the 48 weeks old control rats the length was $42.9 \mathrm{~mm} \pm 0.8$. This latter value is not significantly different from that of the 24 weeks old control rats.

\section{LIGHT MICROSCOPY}

It appears from Table 1 that the cross-sectional fascicular area and the endoneurial area still increased after the age of 24 weeks. This also applies to the mean fibre size and to the mean axon and myelin size.

The morphometric data of peripheral nerve after four weeks of diabetes are shown in Table 2 . The mean fibre area and the axon area of myelinated fibres were decreased by $8.4 \%$ and $13.4 \%$, respectively, the $2 \mathrm{P}$-value being 0.039 and 0.00031 . The endoneurial area and the endoneurial fraction were increased in diabetic rats, the $2 \mathrm{P}$-values being 0.0016 and 0.000025 , respectively.

The results of the insulin experiment are also

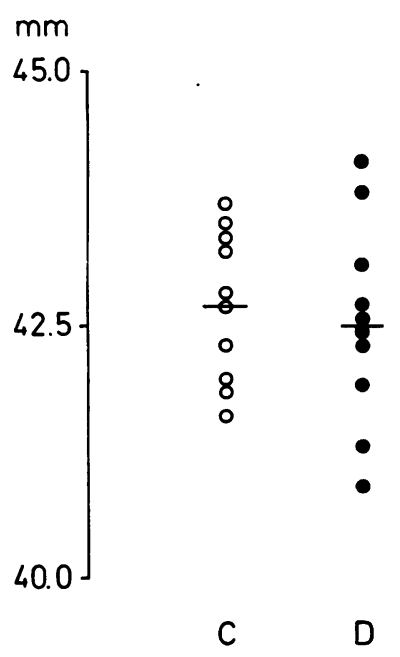

Fig. 2 Individual values of tibial length in each of 10 diabetic (O) and 10 age-matched control rats $(O)$. 
Table 1 Light microscopic data of cross-sectioned common peroneal nerve in control groups of 24,28 , and 48 weeks of age. Results are mean values $\pm S D$

\begin{tabular}{llllllll}
\hline & $\begin{array}{l}\text { Fascicular } \\
\text { area } \\
\left(\mu m^{2} \times 10^{3}\right)\end{array}$ & $\begin{array}{l}\text { “Endoneurial" “Endoneurial" } \\
\text { area } \\
\left(\mu m^{2} \times 10^{3}\right)\end{array}$ & $\begin{array}{l}\text { fraction } \\
\text { fize fibre } \\
\left(\mu m^{2}\right)\end{array}$ & $\begin{array}{l}\text { Mean axon } \\
\text { size } \\
\left(\mu m^{2}\right)\end{array}$ & $\begin{array}{l}\text { Mean myelin } \\
\text { size } \\
\left(\mu m^{2}\right)\end{array}$ & $\begin{array}{l}\text { Axon } \\
\text { myelin } \\
\text { ratio }\end{array}$ \\
\hline 24 weeks $(\mathrm{n}=8)$ & $132 \pm 17$ & $45 \pm 8$ & $0.341 \pm 0.03$ & $43.1 \pm 3.6$ & $20.7 \pm 1.6$ & $22.4 \pm 2.5$ & $0.93 \pm 0.09$ \\
28 weeks $(\mathrm{n}=10)$ & $144 \pm 13$ & $51 \pm 5$ & $0.356 \pm 0.02$ & $47.5 \pm 3.5^{*}$ & $23.8 \pm 1.7^{*}$ & $23.7 \pm 2.2$ & $1.01 \pm 0.08$ \\
48 weeks $(\mathrm{n}=9)$ & $162 \pm 15^{*} \dagger$ & $61 \pm 10^{*} \dagger$ & $0.377 \pm 0.04^{*}$ & $51.8 \pm 5.6^{*}$ & $25.9 \pm 2.9^{*}$ & $26.0 \pm 3.4^{*}$ & $1.01 \pm 0.12$ \\
\hline
\end{tabular}

*Significantly different from 24 week old rats.

†Significantly different from 28 week old rats.

Table 2 Light microscopic data of cross-sectioned common peroneal nerve in the groups of 28 week old controls, age-matched untreated and age-matched insulin-treated diabetic rats. Results are mean values $\pm S D$

\begin{tabular}{llllllll}
\hline & $\begin{array}{l}\text { Fascicular } \\
\text { area } \\
\left(\mu \mathrm{m}^{2} \times 10^{-3}\right)\end{array}$ & $\begin{array}{l}\text { "Endo- } \\
\text { neurial" } \\
\left(\mu \mathrm{m}^{2} \times 10^{-3}\right)\end{array}$ & $\begin{array}{l}\text { "Endoneurial" } \\
\text { fraction }\end{array}$ & $\begin{array}{l}\text { Mean fibre } \\
\text { size } \\
\left(\mu \mathrm{m}^{2}\right)\end{array}$ & $\begin{array}{l}\text { Mean axon } \\
\text { size } \\
\left(\mu \mathrm{m}^{2}\right)\end{array}$ & $\begin{array}{l}\text { Mean } \\
\text { myelin } \\
\text { size } \\
\left(\mu \mathrm{m}^{2}\right)\end{array}$ & $\begin{array}{l}\text { Axon } \\
\text { myelin } \\
\text { ratio }\end{array}$ \\
\hline Control rats $(\mathrm{n}=10)$ & $144 \pm 13$ & $51 \pm 5$ & $0.356 \pm 0.02$ & $47.5 \pm 3.5$ & $23.8 \pm 1.7$ & $23.7 \pm 2.2$ & $1.01 \pm 0.08$ \\
Diabetic rats $(\mathrm{n}=10)$ & $152 \pm 15$ & $64 \pm 9^{*}$ & $0.419 \pm 0.03^{*}$ & $43.5 \pm 4.4^{*}$ & $20.6 \pm 1.5^{*}$ & $22.9 \pm 3.4$ & $0.91 \pm 0.10^{*}$ \\
Insulin treated diabetic rats $(\mathrm{n}=9)$ & $151 \pm 11$ & $54 \pm 11 \dagger$ & $0.354 \pm 0.05 \dagger$ & $49.5 \pm 4.9 \dagger$ & $24.3 \pm 2.4 \dagger$ & $25.2 \pm 2.8$ & $0.97 \pm 0.07$ \\
\hline
\end{tabular}

*Significantly different from the control group.

†Significantly different from the diabetic group.

shown in Table 2. In the insulin-treated group mean fibre and axon size as well as the endoneurial area and the endoneurial fraction all differed significantly from the values of the untreated diabetic rats. None of these parameters differ significantly between controls and insulintreated rats.

\section{NERVE CONDUCTION VELOCITY}

The results of the neurophysiological experiment are shown in Table 3. A gradual decline of nerve conduction velocity was observed as the duration of diabetes increased, the reduction being demonstrable already after one day of disease. After two weeks of diabetes the slowing of the nerve impulse was $4.2 \%(2 \mathrm{P}, 0.0089)$ and after five

Table 3 Conduction velocity of tail nerve in control rats, in diabetic rats with varying duration of diabetes and in insulin-treated diabetic rats. All rats were 28 weeks old. Results are mean values $\pm S D$

\begin{tabular}{lll}
\hline & $\begin{array}{l}\text { Number } \\
\text { of } \\
\text { animals }\end{array}$ & $\begin{array}{l}\text { Conduction } \\
\text { velocity } \\
\left(m s^{-1}\right)\end{array}$ \\
\hline Control rats & 12 & $52.1 \pm 1.6$ \\
24-36 hr after injection of streptozotocin & 14 & $50.4 \pm 2.3^{*} \dagger$ \\
One week of diabetes & 9 & $49.8 \pm 3.1^{*} \dagger$ \\
Two weeks of diabetes & 10 & $49.9 \pm 1.9^{*} \dagger$ \\
Five weeks of diabetes & 11 & $47.4 \pm 1.8^{*}$ \\
Two weeks of insulin-treated diabetes & 9 & $53.1 \pm 2.4 \ddagger$
\end{tabular}

*Significantly different from the control group.

†Significantly different from the group of five weeks.

†Significantly different from the group of two weeks of diabetes. weeks $9 \%(2 \mathrm{P}, 0.0000015)$. The difference between the conduction velocities after two and five weeks duration of diabetes was also statistically significant, the $2 \mathrm{P}$ value being 0.0058 .

Insulin treatment was able to prevent the impairment of peripheral nerve function. The conduction velocity for the group of insulin-treated diabetic rats did not differ significantly from the value of the control rats and was significantly faster than for the group of untreated diabetic rats $(2 \mathrm{P}, 0.0051)$.

\section{ELECTRON MICROSCOPY}

Myelinated nerve fibres Within the test areas an average of 228 myelinated fibres was counted in each rat. The number of myelinated fibres of the common peroneal nerve was $1896 \pm 238$ in the control group and $1798 \pm 204$ in the diabetic group. The difference was not statistically significant.

The morphometric data of the electron microscopic analyses are given in Tables 4 and 5. Mean fibre size was $46.42 \mu \mathrm{m}^{2} \pm 3.24$ in the control group compared to $41.45 \mu \mathrm{m}^{2} \pm 3.45$ in the diabetic group. The difference in fibre size which amounts to $10.7 \%$ is statistically significant $(2 \mathrm{P}, 0.0040)$.

In Table 5, 10 percentiles of individual cumulative size frequency distributions for the control group and for the diabetic group are shown. When identical percentiles are compared it appears that nerve fibres from diabetic rats are smaller for all percentiles, but the differences reached statistical significance only for the 90th and 99th percentiles. 
Table 4 Morphometric data of cross-sectioned myelinated fibres from electron microscopic photomontages of part of common peroneal nerve in 10 diabetic rats and 10 control rats

\begin{tabular}{|c|c|c|c|c|c|c|c|c|c|}
\hline & \multicolumn{3}{|c|}{ Mean fibre, axon, and myelin areas } & \multicolumn{3}{|c|}{$\begin{array}{l}\text { Parameters of regression lines between } \\
\text { axon area and myelin area }\end{array}$} & \multicolumn{3}{|c|}{ Axon organelles } \\
\hline & $\begin{array}{l}\text { Fibre } \\
\text { size } \\
\left(\mu m^{2}\right)\end{array}$ & $\begin{array}{l}\text { Axon } \\
\text { size } \\
\left(\mu m^{2}\right)\end{array}$ & $\begin{array}{l}\text { Myelin } \\
\text { size } \\
\left(\mu m^{2}\right)\end{array}$ & $\begin{array}{l}\text { Slope } \\
\text { coefficient } \\
\text { (a) }\end{array}$ & $\begin{array}{l}Y \text {-axis } \\
\text { intercept } \\
(y)\end{array}$ & $\begin{array}{l}\text { Correlation } \\
\text { coefficient } \\
(r)\end{array}$ & $\begin{array}{l}S E R \\
\text { fraction } \\
\left(\times 10^{3}\right)\end{array}$ & $\begin{array}{l}\text { Mito- } \\
\text { chondrial } \\
\text { fraction } \\
\left(\times 10^{2}\right)\end{array}$ & $\begin{array}{l}\text { Number of } \\
\text { filaments } \\
\left(\text { per } 0.1 \mu \mathrm{m}^{2}\right)\end{array}$ \\
\hline Control rats & $\begin{array}{l}47 \\
40 \\
44 \\
45 \\
44 \\
50 \\
50 \\
49 \\
50 \\
46\end{array}$ & $\begin{array}{l}17 \\
16 \\
18 \\
19 \\
18 \\
20 \\
17 \\
20 \\
22 \\
19\end{array}$ & $\begin{array}{l}30 \\
24 \\
26 \\
26 \\
25 \\
30 \\
33 \\
28 \\
28 \\
27\end{array}$ & $\begin{array}{l}0.45 \\
0.46 \\
0.65 \\
0.55 \\
0.66 \\
0.55 \\
0.51 \\
0.65 \\
0.68 \\
0.55\end{array}$ & $\begin{array}{r}3.6 \\
5.5 \\
0.7 \\
5.0 \\
1.9 \\
3.6 \\
-0.4 \\
2.0 \\
2.3 \\
4.3\end{array}$ & $\begin{array}{l}0.73 \\
0.66 \\
0.80 \\
0.77 \\
0.82 \\
0.73 \\
0.81 \\
0.69 \\
0.78 \\
0.76\end{array}$ & $\begin{array}{l}4.3 \\
5.1 \\
5.5 \\
3.4 \\
6.7 \\
9.9 \\
5.9 \\
5.4 \\
4.5 \\
5.2\end{array}$ & $\begin{array}{l}1.7 \\
2.0 \\
1.5 \\
1.6 \\
1.3 \\
1.6 \\
1.8 \\
1.7 \\
1.5 \\
1.7\end{array}$ & $\begin{array}{l}15 \\
15 \\
16 \\
14 \\
16 \\
14 \\
16 \\
13 \\
12 \\
13\end{array}$ \\
\hline $\begin{array}{l}\text { Mean } \\
\text { SD }\end{array}$ & $\begin{array}{r}46 \\
3\end{array}$ & $\begin{array}{r}19 \\
2\end{array}$ & $\begin{array}{r}28 \\
3\end{array}$ & $\begin{array}{l}0.57 \\
0.09\end{array}$ & $\begin{array}{l}2.8 \\
1.9\end{array}$ & $\begin{array}{l}0.76 \\
0.05\end{array}$ & $\begin{array}{l}5.6 \\
1.8\end{array}$ & $\begin{array}{l}1.7 \\
0.2\end{array}$ & $\begin{array}{r}14 \\
1\end{array}$ \\
\hline Diabetic rats & $\begin{array}{l}41 \\
44 \\
47 \\
34 \\
39 \\
42 \\
40 \\
44 \\
44 \\
40\end{array}$ & $\begin{array}{l}17 \\
18 \\
18 \\
14 \\
16 \\
15 \\
15 \\
16 \\
17 \\
14\end{array}$ & $\begin{array}{l}24 \\
26 \\
29 \\
20 \\
23 \\
27 \\
25 \\
28 \\
27 \\
27\end{array}$ & $\begin{array}{l}0.44 \\
0.53 \\
0.47 \\
0.45 \\
0.57 \\
0.47 \\
0.55 \\
0.43 \\
0.46 \\
0.53\end{array}$ & $\begin{array}{l}6.1 \\
4.7 \\
4.5 \\
4.9 \\
3.4 \\
3.7 \\
4.5 \\
4.1 \\
5.1 \\
2.6\end{array}$ & $\begin{array}{l}0.66 \\
0.70 \\
0.66 \\
0.64 \\
0.76 \\
0.72 \\
0.74 \\
0.70 \\
0.78 \\
0.79\end{array}$ & $\begin{array}{r}5.6 \\
6.5 \\
6.0 \\
12.7 \\
16.4 \\
4.8 \\
7.3 \\
6.3 \\
2.8 \\
8.2\end{array}$ & $\begin{array}{l}1.7 \\
1.5 \\
1.7 \\
1.6 \\
1.4 \\
1.5 \\
1.4 \\
2.0 \\
1.9 \\
1.7\end{array}$ & $\begin{array}{l}14 \\
14 \\
- \\
- \\
\overline{17} \\
14 \\
\overline{16} \\
14\end{array}$ \\
\hline $\begin{array}{l}\text { Mean } \\
\text { SD }\end{array}$ & $\begin{array}{c}41^{*} \\
4\end{array}$ & $\begin{array}{c}16^{*} \\
2\end{array}$ & $\begin{array}{r}25 \\
3\end{array}$ & $\begin{array}{l}0.49^{*} \\
0.05\end{array}$ & $\begin{array}{l}4.4^{*} \\
1.0\end{array}$ & $\begin{array}{l}0.72 \\
0.05\end{array}$ & $\begin{array}{l}7.7 \\
3.9\end{array}$ & $\begin{array}{l}1.6 \\
0.2\end{array}$ & $\begin{array}{r}15 \\
1\end{array}$ \\
\hline
\end{tabular}

*Significantly different from the control group.

Table 5 Fibre size for 10 percentiles of individual cumulative size-frequency distributions of electron micrographs of myelinated fibres in common peroneal nerve. Results are mean values for the diabetic group $(n=10)$ and for age-matched control rats $(n=10)$

\begin{tabular}{lcc}
\hline Percentiles & $\begin{array}{c}\text { Control group } \\
\left(\mu \mathrm{m}^{2} \pm S D\right)\end{array}$ & $\begin{array}{c}\text { Diabetic group } \\
\left(\mu \mathrm{m}^{2} \pm S D\right)\end{array}$ \\
\hline 10th & $7.97 \pm 2.34$ & $6.97 \pm 1.41$ \\
20th & $14.53 \pm 3.51$ & $12.65 \pm 1.63$ \\
30th & $21.59 \pm 3.71$ & $19.29 \pm 2.28$ \\
40th & $30.22 . \pm 4.60$ & $27.13 \pm 3.55$ \\
50th & $39.53 \pm 6.15$ & $35.34 \pm 4.59$ \\
60th & $48.89 \pm 7.47$ & $44.60 \pm 5.75$ \\
70th & $62.32 \pm 12.25$ & $55.22 \pm 7.06$ \\
80th & $75.80 \pm 11.80$ & $67.69 \pm 7.74$ \\
90th & $89.75 \pm 13.20$ & $79.37 \pm 6.64^{*}$ \\
99th & $114.81 \pm 17.20$ & $100.51 \pm 7.09^{*}$ \\
\hline
\end{tabular}

*Significantly different from the control group.

The mean axon size (Table 4) was $18.61 \mu \mathrm{m}^{2} \pm$ 1.72 in control rats as against $15.99 \mu \mathrm{m}^{2} \pm 1.62$ in diabetics. Thus the mean axon size of the diabetic group was reduced by $14.1 \%$, the $2 \mathrm{P}$ value being 0.0026 . The mean myelin size was reduced by $8.5 \%$ the control value being $27.81 \mu \mathrm{m}^{2} \pm 2.73$ and the diabetic value $25.46 \mu \mathrm{m}^{2} \pm 2.50$. However, the difference in myelin size was not statistically significant (2P, 0.060).

To obtain information about the relationship of the cross-sectional axon area to the cross-

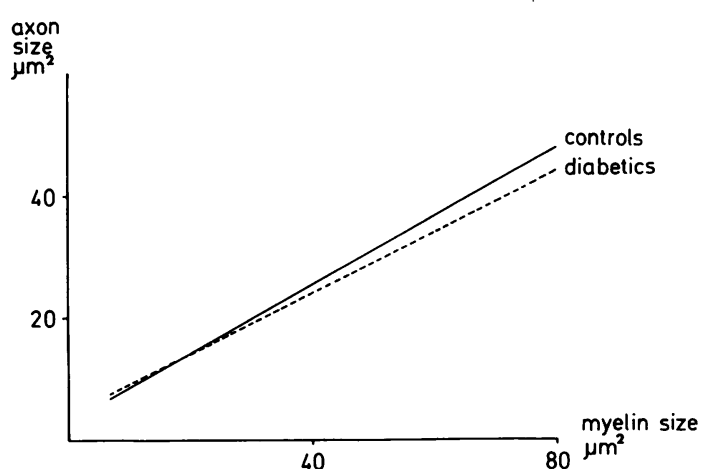

Fig. 3 Mean regression line of the relation ship between axon and myelin area of individual fibres from electron micrographs in control $(n=10)$ and diabetic rats $(n=10)$.

sectional myelin area, correlation analyses were performed for each animal of paired values of single fibres. The relationship of cross-sectional axon area to myelin area is decreased in diabetic rats when compared with age-matched controls. This can be seen from Table 4 . The slope coefficient of individual regression lines was $0.570 \pm 0.085$ in the control group as compared to $0.489 \pm 0.050$ in the diabetic group $(2 \mathrm{P}, 0.019)$. The mean regression lines for the two groups are shown in Fig. 3. 
As to the morphometric analyses of the axon organelles, the SER fraction, the mitochondrial fraction, and the number of neurofilaments are given in Table 4. None of the differences were statistically significant. Furthermore, the number of SER profiles and mitochondrial profiles were found to be very similar in control and diabetic rats, 10.38 \pm 3.03 SER profiles per $100 \mu \mathrm{m}^{2}$ axon in control rats as against $12.42 \pm 4.83$ in diabetics and $25.65 \pm 3.12$ mitochondrial profiles per $100 \mu \mathrm{r}^{2}$ axon in control as against $26.76 \pm 2.42$ in diabetic rats.

Unmyelinated nerve fibres The number of unmyelinated fibres in the common peroneal nerve was $3160 \pm 734$ in the control group and $2864 \pm$ 1139 in the diabetic group. The mean fibre size was $0.468 \mu \mathrm{m}^{2} \pm 0.066$ in control as compared to $0.452 \mu \mathrm{m}^{2} \pm 0.071$ in diabetic rats. Neither these differences nor those of the calibre spectra were statistically significant.

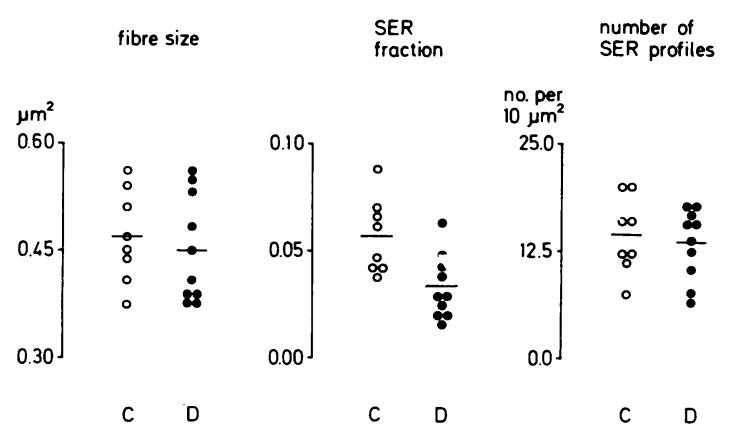

Fig. 4 Mean fibre size, fraction, and number of smooth endoplasmic reticulum profiles in each of eight control $(\mathrm{O})$ and 10 diabetic rats $(\bullet)$.

As to the organelles, however, a pronounced reduction of $40 \%$ of the cross-sectional area fraction of the SER was found in the diabetic group. The SER fractional values were $0.0568 \pm$ 0.017 in control rats and $0.0343 \pm 0.013$ in diabetics $(2 \mathrm{P}, 0.0072)$. The number of SER profiles per $10 \mu \mathrm{m}^{2}$ axon counted in the controls and in the diabetics were $14.60 \pm 4.43$ and $13.60 \pm 4.08$, respectively. Nearly identical values in the two groups were obtained for the mitochondrial fraction as well as for the number of mitochondrial profiles. The mitochondrial fraction in control and diabetic rats were $0.0421 \pm 0.0104$ and $0.0459 \pm$ 0.0079 , respectively, and the number of mitochondrial profiles per $10 \mu \mathrm{m}^{2}$ axon were $8.51 \pm 2.18$ in control and $9.57 \pm 2.27$ in diabetic rats. Individual values of fibre size, SER fraction, and the number of SER profiles are illustrated in Fig. 4.

\section{Discussion}

It has been suggested that the reduction in myelinated nerve fibre calibre in diabetic rats is the result of a failure of growth including retarded skeletal length (Thomas and Sharma, 1976; Sharma et al., 1977; Jefferys et al., 1978). In previous papers we have demonstrated findings hardly compatible with this suggestion. First it was shown that control rats fed a restricted diet leading to a weight loss comparable to that of the diabetic animals have nerve fibres of normal calibre (Jakobsen, 1976a). Secondly, diabetic nerve fibres with reduced calibre were found to have normal nerve internodal length (Jakobsen, 1976b). Finally, the results of the present study show that tibial length is unchanged in our diabetic animals. We therefore conclude that the difference in calibre represents a true neuropathic change rather than a change caused by an ordinary retardation of growth in length.

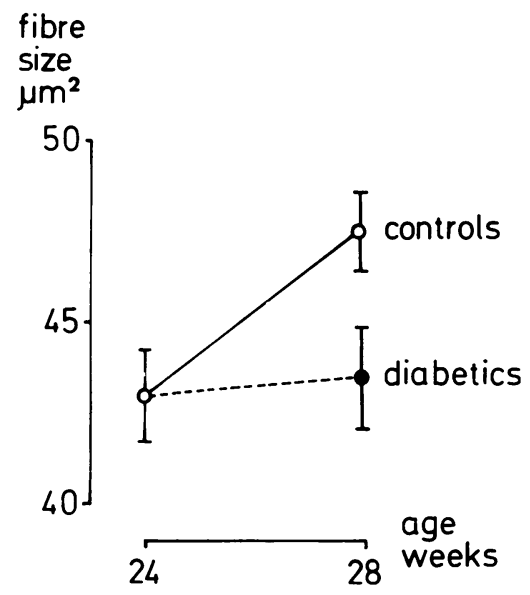

Fig. 5 Mean fibre size and standard errors at the beginning and end of the experiment in two groups of control rats $(\bigcirc)$, and at the end of the experiment in a group of diabetic rats (O).

The electron microscopic part of the present study has confirmed our previous light microscopic finding of reduced calibre in streptozotocin diabetic rats, and the correlation analyses of the crosssectional axon to myelin area of single fibres have given results in accordance with the previous findings of a decreased axon-myelin ratio (Jakobsen and Lundbæk, 1976). Moreover, it has been confirmed that all sizes of fibres seem to be thinner in diabetic rats (Jakobsen, 1976a). 
How does the difference in fibre calibre arise? Figure 5 illustrates what has hapened to fibre size in 28 weeks old diabetic and control rats after the four week experimental periods. If only the fibre size measurements were available it would have been tempting to conclude simply that the diabetic state had caused a relative shrinkage of the fibres or, in other words, had inhibited the increase in fibre calibre normally occurring in rats between the 24th and 28th week. However, the data available here on axons and myelin sheaths must also be taken into consideration.

A decreased axon-myelin relationship can be obtained in at least three different ways. Firstly, it may be the result of axonal shrinkage. Secondly, it can be caused either by an increase in the number of myelin lamellae or by an increased distance between the lamellae. A third possibility is that normal nerves of rats increase the axon size disproportionally to the myelin size between the age of 24 and 28 weeks while this does not occur in diabetic rats.

Whatever constitutes the precise mechanism behind the observed difference in fibre calibre and axon-myelin ratio, there can be no doubt about the observation that a structural axon abnormality is present in peripheral nerve in early streptozotocin diabetes in the rat. It is not decisive for this conclusion whether axonal shrinkage is involved or whether only inhibition of the normal increase in calibre during the experimental period takes place. The change in axon calibre is a prominent feature and may well explain the minor changes of the myelin sheath.

In myelinated axons no change of organelles was demonstrated with the applied microscopic and morphometric techniques. We do not conclude, of course, that the ultrastructure of organelles of myelinated axons is normal.

In unmyelinated fibres a $40 \%$ decrease of the amount of SER was observed in the diabetic rats. Since it is suggested that the compartment for the fast axoplasmic flow is vesicular elements, it might be that the SER decrease is a structural counterpart of a changed fast axonal transport within unmyelinated diabetic nerve fibres (Droz et al., 1975). A decreased transport of transmitter enzymes of myelinated fibres in sciatic nerve of streptozotocin rats with a diabetes duration of four weeks has been reported by Schmidt $e t$ al. (1975). The accumulation of acetylcholinesterase and choline acetylase proximal to a nerve crush was found to be reduced by $20 \%$ and $40 \%$, respectively. Observations to be published from our own laboratory or axonal transport after injection of tritiated leucine and ${ }^{14} \mathrm{C}$-glucosamine into the fifth lumbar dorsal root ganglion of streptozotocin diabetic rats have shown abnormalities of the transport of glycoproteins.

It appears from the insulin experiments that the morphological and neurophysiological alterations observed in these studies can be prevented by insulin treatment leading to normalisation or near normalisation of the blood glucose level. Furthermore, the preventative effect of insulin in streptozotocin diabetic rats implies that the peripheral nerve changes are the result of diabetes, not of a toxic effect of streptozotocin itself.

Nerve fibre calibre increases with age in control rats and so does nerve conduction velocity (Miyoshi and Goto, 1973). Therefore, the effect of duration of diabetes on conduction must be examined in rats of identical age as in the present study. Decreased conduction velocity has been found in several studies of rats with a diabetes duration of from one week up to one year (Eliasson, 1964; Sharma and Thomas, 1974; Greene et al., 1975). Slowing of nerve conduction of large fibres was also demonstrated in the present experiment and, furthermore, a relation between the degree of slowing and the duration of the diabetic state was established. The decrease in conduction velocity developed gradually (Table 3 ) as did the difference in fibre calibre (Fig. 5). It is likely that at least part of the decrease in conduction velocity is explained by the difference in fibre calibre (Jakobsen, 1976a). Slowing of conduction by 3$4 \%$ could be demonstrated as early as 24-36 hours after the application of streptozotocin, at a time when blood glucose had been above $11.1 \mathrm{mmol} \mathrm{1}^{-1}$ $(200 \mathrm{mg} / \mathrm{dl})$ for only $10-18$ hours. This initial impairment of impulse propagation may well be explained by some other factors than difference in fibre calibre-for example, alterations of the axonal membrane at the node of Ranvier.

Finally, the relevance of the findings of the present study to human insulin deficiency diabetes requires discussion.

Segmental demyelination is observed regularly in histological studies of peripheral nerve from patients with several years of diabetes (Thomas and Lascelles, 1966; Chopra et al., 1969). Axonal loss is also present even though it has been claimed to be present particularly in the severe chronic cases (Thomas and Lascelles, 1966) or only in patients who have had diabetic neuropathy of longer duration and of insidious onset (Chopra et al., 1969). However, no conclusions about the interdependence of axon and myelin sheath changes can be drawn from the histological studies available on peripheral nerve changes in longterm diabetes. 
As mentioned above, there is very little information about early structural changes in peripheral nerve of young patients with juvenile diabetes-that is, in a situation similar to that studied in our animal model. Bischoff (1973) mentions changes of axon organelles without the occurrence of segmental demyelination in a qualitative study of sural nerve biopsies from patients of various ages and with various types of diabetes. Very recently, he has reported results of another qualitative electron microscopic study of children and young patients who had had diabetes for less than one year (Bischoff, 1978). Severe axonal changes, again without the presence of segmental demyelination, were shown in this report. The results of quantitative analyses of these preparations will be of considerable interest.

At present it seems reasonable to assume that structural axonal changes occur very early in human beings with juvenile diabetes as in experimental insulin deficiency diabetes, that the axon abnormality is caused by the metabolic derangement characteristic of the diabetic state, and that segmental demyelination, absent in early juvenile diabetes and also in experimental diabetes (Sharma and Thomas, 1974; Jakobsen, 1976b) is a late secondary phenomenon.

\section{References}

Bischoff, A. (1973). Ultrastructural pathology of peripheral nervous system in early diabetes. In Vascular and Neurological Changes in Early Diabetes. Advances in Metabolic Disorders, supplement 2, pp. 441-449. Edited by R. A. Camerini-Dávalos and H. S. Cole. Academic Press: New York and London.

Bischoff, A. (1978). Report at the Aarhus University 50-years Jubilee Symposium: Nervous system abnormalities and nervous disease in diabetes held in Aarhus, Denmark, 31 August-2 September 1978.

Chopra, J. S., Hurwitz, L. J., and Montgomery, D. A. D. (1969). The pathogenesis of sural nerve changes in diabetes mellitus. Brain, 92, 391-418.

Droz, B., Rambourg, A., and Koenig, H. L. (1975). The smooth endoplasmic reticulum: structure and role in the renewal of axonal membrane and synaptic vesicles by fast axonal transport. Brain Research, 93, 1-13.

Elias, H., Henning, A., and Schwartz, D. E. (1971). Stereology: applications to biomedical research. Physiological Reviews, 51, 158-200.

Eliasson, S. G. (1964). Nerve conduction changes in experimental diabetes. The Journal of Clinical Investigation, 43, 2353-2358.

Greene, D. A., De Jesus, P. V., Winegrad, A. I. (1975). Effects of insulin and dietary myoinositol on impaired peripheral motor nerve conduction velocity in acute streptozotocin diabetes. The Jourial of Clinical Investigation, 55, 1326-1336.

Gregersen, G. (1967). Diabetic neuropathy: influence of age, sex, metabolic control, and duration of diabetes on motor conduction velocity. Neurology (Minneapolis), 17, 972-980.

Gregersen, G. (1968a). Variations in motor conduction velocity produced by acute changes of the metabolic state in diabetic patients. Diabetologia, 4, 273-277.

Gregersen, G. (1968b). A study of the peripheral nerves in diabetic subjects during ischaemia. Journal of Neurology, Neurosurgery, and Psychiatry, 31, 175-181.

Jakobsen, J. (1976a). Axonal dwindling in early experimental diabetes. I. A study of cross sectioned nerves. Diabetologia, 12, 539-546.

Jakobsen, J. (1976b). Axonal dwindling in early experimental diabetes. II. A study of isolated nerve fibres. Diabetologia, 12, 547-553.

Jakobsen, J. (1978). Peripheral nerves in early experimental diabetes. Expansion of the endoneurial space as a cause of increased water content. Diabetologia, 14, 113-119.

Jakobsen, J., and Lundbæk, K. (1976). Neuropathy in experimental diabetes. An animal model. British Medical Journal, 2, 278-279.

Jefferys, J. G. R., Palmano, K. P., Sharma, A. K., and Thomas, P. K. (1978). Influence of dietary myoinositol on nerve conduction and inositol phospholipids in normal and diabetic rats Journal of Neurology, Neurosurgery, and Psychiatry, 41, 333-339.

Lundbæk, K. (1953). Long-term Diabetes. E. Munksgaard: Copenhagen, and Lange, Maxwell and Springer: London, New York.

Miyoshi, T., and Goto, I. (1973). Serial in vivo determinations of nerve conduction velocity in rat tails. Physiological and pathological changes. Electroencephalography and Clinical Neurophysiology, 35, 125-131.

Rasch, R. (1979). Control of blood glucose levels in streptozotocin diabetic rats using a long acting treated insulin. Diabetologia, 16, 319-324.

Reske-Nielsen, E., and Lundbæk, K. (1968). Pathological changes in the central and peripheral nervous system of young long-term diabetics. II. The spinal cord and peripheral nerves. Diabetologia, 4, 34 43.

Schmidt, R. E., Matschinsky, F. M., Godfrey, D. A., Williams, A. D., and McDougal, D. B. (1975). Fast and slow axoplasmic flow in sciatic nerve of diabetic rats. Diabetes, 24, 1081-1085.

Seneviratne, K. N., and Peiris, O. A. (1969). The effects of hypoxia on the excitability of the isolated peripheral nerves of alloxan-diabetic rats. Journal of Neurology, Neurosurgery, and Psychiatry, 32, 462-469.

Sharma, A. K., and Thomas, P. K. (1974). Peripheral nerve structure and function in experimental diabetes. Journal of the Neurological Sciences, 23, $1-15$.

Sharma, A. K., Thomas, P. K., and De Molina, A. F. (1977). Peripheral nerve fiber size in experimental diabetes. Diabetes, 26, 689-692. 
Thomas, P. K., and Lascelles, R. G. (1966). The pathology of diabetic neuropathy. Quarterly Journal of Medicine, 35, 489-509.

Thomas, P. K., and Sharma, A. K. (1976). Neuropathy in experimental diabetes. British Medical Journal, 2,478 .
Weibel, E. R., and Bolender, R. P. (1973). Stereological techniques for electron microscopic morphometry. In Principles and Techniques of Electron Microscopy, volume 3, pp. 237-296. Edited by M. A. Hayat. Van Nostrand Reinhold Company: New York. 